\title{
Fathers vs. Mothers: Evaluation of Parent Proxies for Early Childhood Dental Visits in an Indian Population
}

\author{
Aafreen Valiya Manathal $^{1}$, Varghese Chacko ${ }^{2 *}$, Srikant Natarajan ${ }^{3}$ \\ ${ }^{1}$ Bangalore, India \\ ${ }^{2}$ Department of Pedodontics \& Preventive Dentistry Sri Sankara Dental College, Trivandrum, Kerala, India \\ ${ }^{3}$ Department of Oral Pathology, Manipal University, Mangalore
}

Received: June 24, 2016; Accepted: June 30, 2016; Published: July 12, 2016

*Corresponding author: Dr. Varghese Chacko, B.D.S, M.D.S, Professor, Department of Pedodontics \& Preventive Dentistry, Sri Sankara Dental College, Trivandrum, Kerala, India, Tel: +91-994-590-3313;E-mail: varghesetvm@yahoo.co.in

\begin{abstract}
Context: Dental disease during early childhood can affect the oral health related quality of life, without timely treatment; which can be facilitated by the child's caregiver.

Objectives: To study the differences in perception of early childhood oral heath related quality of life between fathers and mothers having children below six years of age, and to establish which parent can act as the child's dental proxy.

Study Design: A questionnaire study was conducted among parents of sixty-nine children visiting the Department Of Pedodontics, Manipal College of Dental Sciences, Mangalore.

Methods and Material: The children were examined for the dmft (decayed, missing, filled teeth) scores, while their parents were asked to fill the ECOHIS (Early Childhood Health Impact Scale) questionnaire. The correlation between the ECOHIS scores and dmft was then compared.
\end{abstract}

Statistical analysis used: A paired t-test was used to compare the fathers' and mothers' responses. The reliability of the questionnaire and the parents' responses was determined using Cronbach's alpha. Correlation of ECOHIS scores to the dmft values was done using a linear regression model.

Results: The mothers' ECOHIS responses had a significant correlation with the dmft scores of the child. Hence, the mothers had a more accurate knowledge about the child's oral health than the fathers.

Conclusion: The study helped determine that mothers can be reliable dental proxies for their children below six years of age.

Keywords: Child's dental proxy; dmft; ECOHIS

\section{Introduction}

The assessment of quality of life is an integral part of evaluating health programs [1]. Oral Health Related Quality of Life (OHRQOL)evaluates the impact of oral health problems on an individual's physical, mental, social health and well-being [2]. In recent years, numerous instruments have been developed to improve and validate OHRQOL in children and adolescents [3, 4 ,5]. One such instrument is the Early Childhood Oral Health
Impact Scale (ECOHIS) which was developed and validated in English in the United States [2].

The Early Childhood Oral Health Impact Scale (ECOHIS) is a thirteen question instrument designed to assess the impact of oral health problems and related treatment on the quality of life of preschool children (below six years of age) and their families. It is divided into two parts, namely the Child Impact section and Family Impact section. As the name suggests, the child impact scale assesses the impact of oral disease on the child, whereas the family impact scale assesses the impact of oral disease on the family.

The questionnaire is scored using a simple five-point Likert Scale, with responses ranging from "never" to "very often" (equivalent to a score of 0 to 4 respectively) with a "don't know" option. The individual item scores are simply added to create a total scale score which ranges from 0 to 52 . Higher scores denote a greater oral health impact and/or poorer Oral Health Related Quality of Life (OHRQOL) and vice versa.

ECOHIS has been found to be adaptable to a variety of languages and cultures, having been validated in French [6], Spanish [7], Portuguese [8] and Farsi [9].

Preschool children may suffer from a number of oral health problems such as teething pains, early childhood caries (ECC) and dental trauma. According to a study done in Bangalore in 2012, the prevalence of ECC was $27.5 \%$ and the mean dmft score was 0.854 [10]. The prevalence Of ECC has a significant effect on the child's quality of life (QOL) [11]. The QOL of a child with ECC only improves with proper dental treatment [5].

Children below sixyears of age have difficulty in understanding basic health concepts and are incapable of adequately assessing themselves [12]. Children's self-concept and health recognition is age dependent, and results from continuous cognitive, emotional, social and language development. According to child development psychology, the age of six marks the beginning of abstract thinking and self-concept [13]. This necessitates the ECOHIS questionnaire to be filled by a parental proxy. 
Societal, cultural and economic changes in the past few decades have led to a change in parenting roles. In the present day family, fathers have to take an active role in everyday care and nurturing of children. Medical research has shown that fathers are becoming more involved with their children, and partake in attending the child's well-care visits $[14,15]$. It has also been reported that involvement of both parents is ideal for the child's development and well-being. A study done in Saudi Arabia, to determine perceptual differences between fathers and mothers, on the impact that oral health has on the child, suggested fathers have significantly less accurate knowledge of the OHRQOL of their children than mothers [16]. This gives rise to the question as to whether the father can act as a suitable dental proxy for the child in our society.

Thus this study aims to determine which parent is the more suitable dental proxy for his/her child by studying the differences in perceptions of early childhood oral health related quality of life between fathers and mothers.

\section{Subjects and Methods}

Institutional ethics approval was obtained before the commencement of the study. The English version of the Early Childhood Oral Health Impact Scale (ECOHIS) was translated to Kannada and the validity of the questionnaire was assessed by the well-accepted forward-backward translation technique recommended by Guillemin et al [17].

A written informed consent was obtained from the parents of the children participating in the study. The questionnaire, either the English or Kannada version, depending on the parent's preference, was then administered to the parents. A total of sixty-nine children, aged two to six years of age, visiting the Department of Pedodontics, Manipal College of Dental Sciences, Mangalore were included in the study. To ensure pairing between the responses of the father and the mother, only children accompanied by both the parents were included in the study. A comprehensive extra-oral and intra-oral examination of the children was also done and their $\mathrm{dmft}$ scores were recorded using a ball ended probe and mouth mirror, in a dental chair with illumination.

The completed questionnaires were collected and the responses were scored, with the scores ranging from zero (for never) to a maximum of four (for very often). The total scores for the Child Impact section, the Family Impact Section and the ECOHIS overall were calculated, along with the number of "don't know" responses. These were then compared between the fathers and the mothers.

The data collected was analysed using SPSS (version17, IBM, Armnok, NY, USA). Demographic data such as age of the child, age of the parent and mean $\mathrm{dmft}$ score were tabulated.

The reliability of the questionnaire and the fathers' and mothers' responses was determined using Cronbach's alpha. The fathers' and mothers' responses were then compared using paired t-test, in three categories - child impact, family impact and ECOHIS overall. Also, a linear regression model was made using the dmft as the dependent variable and the ECOHIS scores of the fathers and the mothers as co-variants, to determine which parent had a more accurate insight into their child's oral health.

\section{Results}

A total of sixty-nine children participated in the study, forty boys and twenty-nine girls, with an average age of $4.96 \pm 1.11$ years. Among the parents that participated in the study, the mean age of the fathers was 38.9 years \pm 6.6 years; while the mean age of the mothers was 31.1 years \pm 4.8 years. The mean $\mathrm{dmft}$ score for the study sample was $5.36 \pm 3.0$. Table 1

The fathers had a much higher number of don't know responses (105) as compared to the mothers (33) and this difference was found to be statistically significant $(p<0.001)$. The mothers recorded higher scores for each of the sections of the ECOHIS questionnaire, namely the child impact, family impact and ECOHIS score overall as compared to the fathers Figure 1.

The paired t-test done to compare the fathers' and mothers' responses on their views on the impact of the child's oral health, showed that the fathers' and mothers' views were significantly different $(\mathrm{P}<0.001)$ regarding the impact of oral health problems on the child, and the overall impact. However, the views of both the fathers and mothers regarding the impact the child's oral health problems had on the family, were not significantly different $(\mathrm{P}=0.211)$ Table 2.

The reliability of parent responses was calculated using Cronbach's alpha. There was good agreement between fathers and mothers responses for both the family impact and child

\begin{tabular}{|c|c|c|c|c|}
\hline & & Father's Age & Mother's Age & $\mathrm{dmft}$ \\
\hline \multirow{2}{*}{$\mathrm{N}$} & Valid & 66 & 63 & 69 \\
\hline & Missing & 3 & 6 & 0 \\
\hline \multicolumn{2}{|c|}{ Mean } & 38.97 & 31.13 & 5.36 \\
\hline \multicolumn{2}{|c|}{ Std. Deviation } & 6.619 & 4.878 & 3.044 \\
\hline \multicolumn{2}{|c|}{ Range } & 34 & 20 & 12 \\
\hline \multicolumn{2}{|c|}{ Minimum } & 28 & 24 & 1 \\
\hline \multicolumn{2}{|c|}{ Maximum } & 62 & 44 & 13 \\
\hline
\end{tabular}

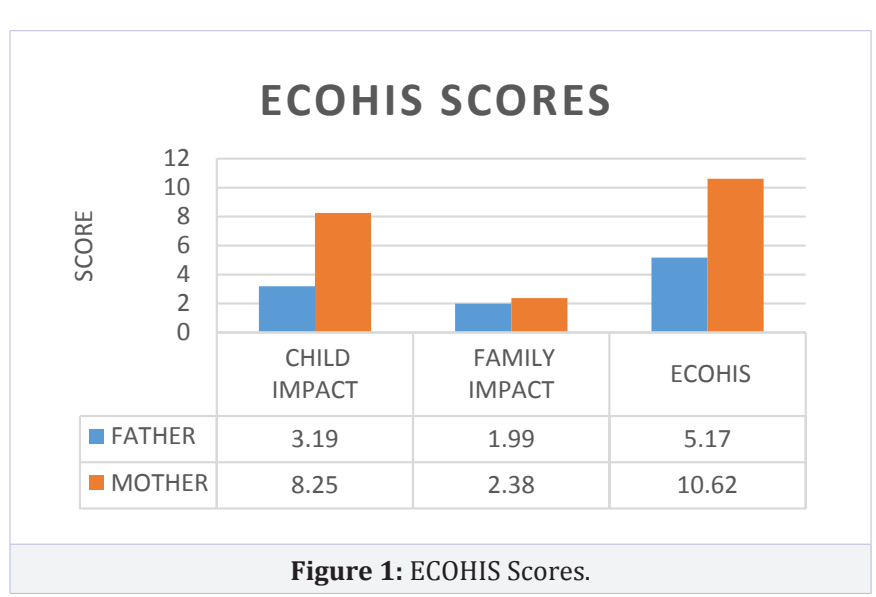


Table 2: Comparison of Fathers and Mothers Scores.

\begin{tabular}{|c|c|c|c|c|c|c|c|c|c|}
\hline & & \multirow{2}{*}{$\begin{array}{l}\text { Mean } \\
\text { Score }\end{array}$} & \multirow[b]{2}{*}{$\mathbf{N}$} & \multirow{2}{*}{$\begin{array}{l}\text { Standard } \\
\text { Deviation }\end{array}$} & \multicolumn{2}{|c|}{ Paired Differences } & \multirow[b]{2}{*}{$\mathbf{T}$} & \multirow[b]{2}{*}{ df } & \multirow[b]{2}{*}{ P VALUE } \\
\hline & & & & & $\begin{array}{c}\text { Mean } \\
\text { Difference }\end{array}$ & Std. Deviation & & & \\
\hline \multirow{2}{*}{$\begin{array}{l}\text { Child } \\
\text { Impact }\end{array}$} & Father & 3.19 & 69 & 5.574 & \multirow{2}{*}{-5.058} & \multirow{2}{*}{5.501} & \multirow{2}{*}{-7.638} & \multirow{2}{*}{68} & \multirow{2}{*}{$<0.001^{*}$} \\
\hline & Mother & 8.25 & 69 & 5.939 & & & & & \\
\hline \multirow{2}{*}{$\begin{array}{l}\text { Family } \\
\text { Impact }\end{array}$} & Father & 1.99 & 69 & 3.027 & \multirow{2}{*}{-0.391} & \multirow{2}{*}{2.574} & \multirow{2}{*}{-1.263} & \multirow{2}{*}{68} & \multirow{2}{*}{0.211} \\
\hline & Mother & 2.38 & 69 & 2.269 & & & & & \\
\hline \multirow{2}{*}{ Ecohis } & Father & 5.17 & 69 & 7.784 & \multirow{2}{*}{-5.449} & \multirow{2}{*}{7.099} & \multirow{2}{*}{-6.376} & \multirow{2}{*}{68} & \multirow{2}{*}{$<0.001 *$} \\
\hline & Mother & 10.62 & 69 & 7.025 & & & & & \\
\hline
\end{tabular}

$* \mathrm{P}<0.05$ is significant; $\mathrm{P}<0.01$ is highly significant

impact parts of the questionnaire. Table 3

The reliability of the fathers' and mothers' responses was also determined using Cronbach's alpha and both the fathers' and mothers' responses were found reliable, as Cronbach's alpha value is greater than 0.8 . Table 4

Finally, the linear regression model was done in order to compare the fathers' and mothers' responses with the dmft scores Table 5 \& Table 6 . It showed a positive correlation between the dmft scores and the fathers' and mothers' ECOHIS scores.

\section{Linear regression}

However, when a linear regression model was made,

Table 3: Reliability of Parent Responses.

\begin{tabular}{|c|c|}
\hline Category & Cronbach's alpha \\
\hline Child Impact & $0.912^{*}$ \\
\hline Family impact & $0.805^{*}$ \\
\hline \multicolumn{2}{|c|}{${ }^{*}$ Cronbach's alpha $>0.7$ is acceptable } \\
\hline
\end{tabular}

Table 4: Reliability of the fathers' and mothers' responses.

\begin{tabular}{|c|c|}
\hline Parent's responses & Cronbach's alpha \\
\hline Father & $0.880^{*}$ \\
\hline Mother & $0.706^{*}$ \\
\hline${ }^{*}$ Cronbach's alpha $<0.7$ is acceptable \\
\hline
\end{tabular}

Table 5: Relationship between fathers' responses and dmft.

\begin{tabular}{|c|c|c|c|c|c|c|}
\hline \multicolumn{7}{|c|}{ Coefficients** } \\
\hline & \multirow{2}{*}{ Model } & \multicolumn{2}{|c|}{$\begin{array}{l}\text { Unstandardized } \\
\text { Coefficients }\end{array}$} & \multirow{2}{*}{\begin{tabular}{|c}
$\begin{array}{c}\text { Standardized } \\
\text { Coefficients }\end{array}$ \\
Beta \\
\end{tabular}} & \multirow{2}{*}{$\mathbf{t}$} & \multirow{2}{*}{$\begin{array}{c}\text { P } \\
\text { VAL- } \\
\text { UE }\end{array}$} \\
\hline & & B & $\begin{array}{l}\text { Std. } \\
\text { Error }\end{array}$ & & & \\
\hline \multirow{2}{*}{1} & (Constant) & 4.816 & .428 & & 11.259 & .000 \\
\hline & $\begin{array}{l}\text { FATHER } \\
\text { ECOHIS }\end{array}$ & .106 & .046 & .270 & 2.293 & $.025^{*}$ \\
\hline & endent Var & ble: dn & ${ }^{*} \mathrm{P}<0$ & is significant & & \\
\hline
\end{tabular}

comparing both father's and mother's responses simultaneously, with the child's dmft; it showed that mother's ECOHIS has a significant correlation, while the father's responses do not. Table 7\& Figure 2

\section{Discussion}

Pediatric dentists often rely on parents to provide information on their child's oral health and the impact it has on their child. The validity of the information provided by the parent and thus whether the parent is a reliable proxy for the child continues to be researched extensively [18]. With respect to oral health, studies have shown that even though parent reports may be incomplete, the information obtained from parents is valid, reliable and useful [19].

In India, traditionally, mothers have been more involved in childcare, with fathers playing the role of the "bread winner" in the family. However with medical research conclusively providing evidence that fathers have an important role to play in complete and healthy infant and child development, the scenario is slowly changing. Also societal, cultural and economic factors have resulted in more mothers choosing a profession. This has resulted in the child being accompanied by the father for his/ her dental visit. Thus it is important to evaluate whether fathers can act as reliable proxies for children during their dental visits.

In the present study, the early childhood oral health impact scale (ECOHIS) has been used to assess the difference in perception of parents on oral health related quality of life (OHRQoL) of their children due to its cross cultural validity and adaptability across a variety of languages and cultures [17].

Literature evaluating and comparing parental perception on children's oral health and their related quality of life is limited. ${ }^{[16]}$ In the present study, mothers scored higher in all sections of the ECOHIS questionnaire thus suggesting that mothers displayed greater concern about the child's oral health and the impact it had on the child and family. This is in contrast to the findings of S.C Pani et al who reported that fathers gave higher scores for ECOHIS as compared to mothers among Saudi parents [16]. Zhang et al also reported fathers scoring higher than mothers while studying parental perception of orthodontic treatment needs using the $C P Q_{11-14}$ [20].The findings of this study suggest that the fathers and mothers did not have a significant difference 
Table 6: Relationship between mothers' responses and dmft.

\begin{tabular}{|c|c|c|c|c|c|c|}
\hline \multicolumn{7}{|c|}{ Coefficients** } \\
\hline & \multirow{2}{*}{ Model } & \multicolumn{2}{|c|}{ Unstandardized Coefficients } & \multirow{2}{*}{$\begin{array}{c}\text { Standardized Coefficients } \\
\text { Beta }\end{array}$} & \multirow{2}{*}{$\mathbf{t}$} & \multirow{2}{*}{ Sig. } \\
\hline & & B & Std. Error & & & \\
\hline \multirow{2}{*}{1} & (Constant) & 3.592 & .621 & & 5.785 & .000 \\
\hline & Mother ECOHIS & .167 & .049 & .385 & 3.412 & $.001^{*}$ \\
\hline
\end{tabular}

Table 7: Relationship between fathers' and mothers' responses and $\mathrm{dmft}$.

\begin{tabular}{|c|c|c|c|c|c|c|}
\hline \multicolumn{7}{|c|}{ Coefficients $^{\mathrm{a}}$} \\
\hline & \multirow{2}{*}{ Model } & \multicolumn{2}{|c|}{ Unstandardized Coefficients } & \multirow{2}{*}{$\begin{array}{c}\text { Standardized Coefficients } \\
\text { Beta }\end{array}$} & \multirow{2}{*}{$\mathbf{T}$} & \multirow{2}{*}{ Sig. } \\
\hline & & B & Std. Error & & & \\
\hline \multirow{3}{*}{1} & (Constant) & 3.633 & .627 & & 5.794 & .000 \\
\hline & Father ECOHIS & .034 & .053 & .086 & .635 & .528 \\
\hline & Mother ECOHIS & .146 & .059 & .338 & 2.503 & .015 \\
\hline
\end{tabular}

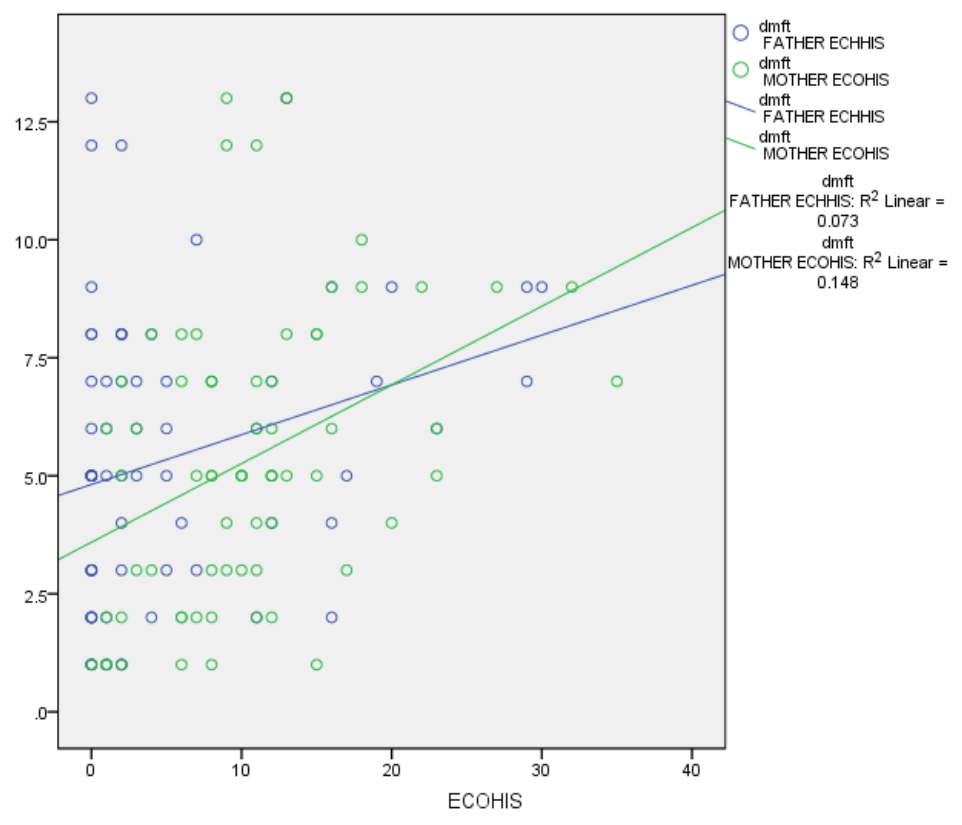

Figure 2: Graph showing the relationship between the fathers' and mothers' responses and the child's dmft scores.

in opinion, on the impact the child's oral health problems had on the family; while their opinions significantly varied when it came to the impact it had on the child at a personal level, and the overall quality of living of the child. This could be due to the fact that in the study population, the mothers were more likely to be involved with childcare and thus were more aware of the impact the child's oral health had on the child.

In the present study, fathers reported a significantly higher number of don't know responses than the mothers and most of these don't know responses were in the child-impact section of the questionnaire. This is similar to the findings of S.C Pani et $a l$ in their study on Saudi parents [16]. Even though the "don'tknow" responses do not affect the results of a study similar to the present one, this highlights a poorer awareness among fathers of the numerous impacts poor oral health can have on their child.

The linear regression model revealed a positive correlation between both parent responses and the ' $\mathrm{dmft}$ ' of their child. This in contrast to the findings of the study done among Saudi parents where the fathers' responses were not found to have any correlation with the 'dmft' of their children [16]. This suggests that in the study population, fathers were aware of their child's oral health needs. However, only mothers' responses were 
found to have a significant correlation with the child's 'dmft'. Thus, suggesting that mothers were more likely to have a more accurate insight on the child's oral health problems and its impact on the child's quality of life. Thus the findings of the present study suggest that while both the father and mother could be relied on to provide an insight on the child's oral health, it is the mother who was more likely to have a more complete and accurate knowledge of the child's oral health needs.

In the present study the influence of factors such as age of the parents, socio-economic status and birth order were not considered. Further studies assessing the impact of these factors will provide us with a better understanding of parental perception on child oral health and related quality of life.

\section{Conclusion}

The present study suggests that, in an Indian population, while both the father and mother can be relied on to provide an insight on the child's oral health, it is the mother who was more likely to have a more complete and accurate knowledge of the child's oral health needs. Therefore, the study has helped establish that, for children below six years of age, the mother is more suitable to act as the child's dental proxy.

\section{Acknowledgement}

The authors wish to acknowledge and thank the Department of Pedodontics, Manipal College of Dental Sciences, Mangalore, India, for the assistance and guidance provided, and the willingness to participate in the survey.

\section{References}

1. Kaplan RM. The significance of quality of life in health care. Qual Life Res. 2003;12 suppl-1:3-16.

2. Pahel BT, Rozier RG, Slade GD. Parental perceptions of children's oral health: The Early Childhood Oral Health Impact Scale (ECOHIS). Health Qual Life Outcomes. 2007;5-6. doi:10.1186/1477-7525-5-6

3. Simon AE, Chan KS, Forrest CB. Assessment of Children's HealthRelated Quality of Life in the United States with a Multidimensional Index. Pediatrics. 2008;121(1):e118.

4. Jokovic A, Locker D, Stephens M, Kenny D, Tompson B, Guyatt G. Measuring parental perceptions of child oral health-related quality of life. J Public Health Dent. 2003;63(2):67-72.

5. Filstrup SL, Briskie D, Fonseca M, Lawrence L, Wandera A, Inglehart MR. Early Childhood Caries and Quality of Life: Child and Parent Perceptives. Pediatric Dentistry. 2003;25(5):431-435.

6. Li S, Veronneau J, Allison PJ. Validation of a French language version of the Early Childhood Oral Health Impact Scale (ECOHIS). Health Quality Life Outcomes. 2008;6:9. doi:10.1186/1477-7525-6-9.

7. Bordoni N, Ciaravino O, Zambrano O, Villena R, Beltran-Aguilar E, Squasi A. Early Childhood Oral Health Impact Scale (ECOHIS) translation and validation in Spanish language. Acta Odontol Latinoam. 2012;25(8):270-278.

8. Martin-Junior P, Ramos-Jorge J, Paiva SM, Marques LS, Ramos-Jorge ML. Validation of Brazilian version of Early Childhood Oral Health Impact Scale (ECOHIS). Cad Saude Publica. 2012;28(2):367-374.

9. Jabarifar SE, Golkari A, Ijadi MH, Jafarzadeh M, Khadem P. Validation of a Farsi version of the early childhood oral health impact scale (F-ECOHIS). BMC Oral Health. 2010;10:4. doi:10.1186/1472-6831$10-4$.

10. Subramaniam P, Prashanth P. Prevalence of early childhood caries in 8-48 month old preschool children of Bangalore city, South India. Contemporary Clinical Dent. 2012;3(1):15-21. doi:10.4103/0976237X.94540.

11. Low W, Tan S, Schwartz S. The effect of severe caries on the quality of life in young children. Pediatr Dent. 1999;21:325-326.

12. Rebok G, Riley A, Forrest C, Starfield B, Green B, Robertson J, et al. Elementary school-aged children's report of their health: a cognitive interviewing study. Qual of Life Res 2001;10(1):59-70.

13. Dr. Arathi Rao. Principles and Practice of Paedodontics. First Edition. Jaypee Publishers;2008:68-69.

14.Garfield CF, Isacco A. Fathers and the well-child visit. Pediatrics 2006;117(4):e637-e645.

15. Moore T, Kotelchuck M. Predictors of Urban fathers' involvement in their child's health care. Pediatrics. 2004;113(3 pt 1):574-580.

16. Pani SC, Badea L, Mirza S, Elbaage N. Differences in perceptions of early childhood oral health related quality of life between fathers and mothers in Saudi Arabia. Intl Journal of Paediatric Dentistry. 2012;22(4):244-249. doi:10.1111/j.1365-263X.2011.01185.x.

17. Guillemin F, Bombardier C, Beaton D. Cross-cultural adaptation of health-related quality of life measures: literature review and proposed guidelines. J Clin Epidemiol. 1993;46(12):1417-1432.

18. Whiteman D, Green A. Where in lies the truth? Assessment of agreement between parent proxy and child respondents. Int J Epidemiol 1997;26(4):855-859.

19. Barbosa TS, Gavia o MBD. Oral health-related quality of life in children: Part III. Is there agreement between parents in rating their children's oral health-related quality of life? Asystematic review. Int J Dent Hygiene. 2008;6(2):108-113. doi:10.1111/j.16015037.2007.00271.x

20.Zhang M, McGrath C, Hagg U. Who knows more about the impact of malocclusion on children's quality of life, mothers or fathers? Eur J Orthod. 2007;29(2):180-185. 